THE ROLE OF SOCIO-SPATIAL CONTEXT IN THE

HABIT-GOAL INTERFACE OF AUDIOVISUAL MEDIA CONSUMPTION

Cédric Courtois, Frederik De Grove, and Lieven De Marez

iMinds-MICT-Ghent University, Department of Communication Sciences, Belgium

Corresponding author:

Cédric Courtois

iMinds-MICT-Ghent University, Department of Communication Sciences

Korte Meer 7-9-11

9000 Ghent, Belgium

Cedric.Courtois@Ugent.be

Tel: +3292649154

http://www.mict.be

\title{
Acknowledgements
}

The authors would like to thank all participants in the present study for their hospitality, dedication and openness during the interviews. For privacy reasons, the participants were given fictive names. 
THE ROLE OF SOCIO-SPATIAL CONTEXT IN THE

HABIT-GOAL INTERFACE OF AUDIOVISUAL MEDIA CONSUMPTION

\begin{abstract}
This article addresses the role of socio-spatial context in audiovisual media consumption by adopting a multi-paradigmatic approach that combines the Theory of Media Attendance with Domestication Theory. We propose a framework that inquires how goals and habits interface with each other as explanatory factors of consumption and how the role of socio-spatial cues can be understood. Survey results show that different socio-spatial settings are associated with distinct explanations by goals and habits. Moreover, follow-up interviews indicate that these differences are best understood when framed in everyday life family dynamics. The results confirm findings of classical research, albeit showing that the patterns from these studies are increasingly pressured by novel dynamics in the contemporary media environment.
\end{abstract}

\title{
INTRODUCTION
}

In today's pervasive media environment, various devices furnish the consumption of audiovisual materials through a wide range of channels and in a myriad of social and physical spaces. As a consequence, the once so rigid scheme of the nuclear family gathering around the living room television set is pressured (Lull, 1999). The evolution in the number of affording technologies and consumption spaces, coupled with the virtually unrestricted access to content through numerous channels have brought about a need to recapture the concept of 'television' (Courtois, Verdegem \& De Marez, 2012). More specifically, it has become increasingly unclear what watching television entails, as for one person it might be the classic configuration with a large screen in the living room, whereas for someone else, this would include catching up a series or news items on a mobile device. In this article we frame 
audiovisual consumption as the viewing of (professionally) produced video products, regardless of device, channel, and surroundings. Moreover, we consider how this increasing diversity in options plays down in terms of different constellations of social presence and spatial environments and how it affects the interplay between goals and habitual behavior. By taking into account goals, we link up to the traditional Uses \& Gratifications paradigm (Rubin, 2002). By drawing on the habit concept we acknowledge that not all behavior is motivated per se (LaRose, 2010). Hence, we first question whether distinct patterns of sociospatial context affect the habit-goal interface of audiovisual consumption. Next, we aim to understand these relations by drawing upon Domestication Theory (Silverstone \& Haddon, 1996). This social-constructivist perspective explicitly addresses the formation of media consumption routines.

\section{The habit-goal interface}

The reason why people use media is one of the central themes in media studies, with Uses \& Gratifications (U\&G) as one of the most attractive and prominent paradigms for empirical research (Ruggiero, 2000). Developed during the second half of the previous century, it steadily evolved from merely descriptive research into a more concrete phase of operationalization. $U \& G$ draws upon the assumptions of an active audience that is conscientiously aware of its needs and rationally selects the best means to gratify these needs from a range of alternatives, including various media (Katz, Blumler, \& Gurevitch, 1974). In

early empirical research, this has led to a broad variety of data-driven typologies of gratifications which are considered to explain why media are used, albeit to a limited extent (Palmgreen, Wenner, \& Rosengren, 1985). In a subsequent phase, theories were built and explanatory models were tested (Palmgreen \& Rayburn, 1985). The most remarkable attempts draw upon social-psychological reasoning, considering $U \& G$ as an expectancy-value process (Galloway \& Meek, 1981; Palmgreen \& Rayburn, 1985; Van Leuven, 1981). Still this 
perspective does not fend off the major criticisms that exist up until today. Namely the inevitable take on the ultimately rational individual, perfectly aware of mental states. This does not comply with the observation that, in general, most of our behavior is habitual (LaRose, 2010). More specifically, habitual behavior - both provoked by internal goals and external circumstances - comprises the following elements: it lacks awareness, is difficult to control and is prone to cognitive efficiency, which distinguishes them from mere repeated behavior (LaRose, 2010). In fact, research has shown that the effects of previous behavior, attitude and intention on behavioral frequency tend to diminish when controlling for habitual behavior. (Verplanken, Aarts, van Knippenberg, \& Moonen, 1998).

Still, media consumption should not be seen as solely explained by automaticity. Nor is it the isolated result of cautious forethought. In most cases, habits are actually residues of long-term repeated behavior, encouraged by underlying goals. Also, the causality can be reversed, as habits are informative of people's goals and lead people to contexts in which habitual behavior is prompted (i.e. habits become motivators). Moreover, goals can interact with habits so that they are steadily preserved. Hence, models that propose to explain behavior need to incorporate both modes as related, though distinct constructs (Wood \& Neal, 2007). In media studies, this has been accomplished by the Theory of Media Attendance (TMA), which merges U\&G with Social Cognitive Theory (LaRose \& Eastin, 2004; LaRose, Mastro, \& Eastin, 2001). The latter views behavior as a result of the triadic reciprocal relationship between individuals, their behavior and their environments. Multiple learning sources are identified to acquire new behavior, which is exercised after forethought and are subject to self-regulation. People do not only learn through direct experience (enactive leaning), they also learn vicariously, by observing models. What is more, at the onset of behavior, we assess our efficacy (i.e. self-efficacy) to attain favorable outcomes that reflect six theoretically embedded and empirically supported categories of inherent incentive 
motivators for human behavior (novel, self-reactive, social, status, monetary and activity; Bandura, 1986). In fact, in the model of media attendance, ad hoc gratifications are replaced by these theoretically embedded incentives. A brief literature review by LaRose et al (2001) revealed that four major incentive categories are commonly covered by U\&G typologies: activity $(\approx$ entertainment $)$, social $(\approx$ interaction $)$, novel $(\approx$ information $)$ and self-reactive $(\approx$ escapism). In practice, these motivators are operationalized as expected outcomes and serve as indicators of a second-order construct in the model of media attendance.

The model of media attendance has been used to gain insight in various cases such as Internet use (LaRose \& Eastin, 2004; LaRose, et al., 2001; Peters, Rickes, Jöckel, Von Criegern, \& Van Deursen, 2006), mobile phone adoption (Peters, 2009), video game attendance (Lee \& LaRose, 2007), and illegal music downloading (LaRose \& Kim, 2007). In each situation, the combination of expected outcomes (goals) and habit strength has demonstrated to account for a substantial amount of variance in the frequency of media consumption. This is a major merit that to our knowledge was unprecedented in gratifications research. Nevertheless, a few scholars recognized the importance of habit quite early. For example, Rubin (1983) incorporated habit in a television viewing typology, yet treating it as a gratification like any other (LaRose, 2009). Later on, he made a distinction between instrumental and more ritualistic gratifications, like relaxation and passing time (Rubin, 1984). Still, we hold the position that every outcome is prone to automaticity. Moreover, Rubin persisted to consider these types of gratifications as part of an active process and positioned it as a need, which implies a contradiction with the two-route socio-cognitive view, that sees habit as a function of prior explicit motivators.

\section{The importance of the socio-spatial context}

When a habit is installed, entering the associated context primes the coded responses, making them readily available and prone to automatic execution without the necessity of goal 
mediation (Wood, Quinn, \& Kashy, 2002). Of course, present experiences do not exactly fit prior experiences, but nonetheless similar surroundings tend to make us revert to behaviors frequently performed in the past. A more formal approach to context stability is offered by Wood, Quinn and Kashy (2002) insofar that they consider a context stable '... to the extent that they present the same contextual cues integral to performing the response and to the extent that they are similarly conducive to fulfilling an actor's goals' (p. 1282). Situations may vary in a number of characteristics, but if those cues that evoke a response are present, it can be considered stable. In contrast, unstable contexts challenge the smooth initiation, execution and termination of practiced behavior (Wood, et al., 2002). When people enter new contexts, they have to think to find out the most suitable response, whereas in familiar situations there is little to no need to perform this operation. Behavior that is rarely performed in a stable context, or repeated behavior performed in a variety of contexts is much less likely to become a habit (Danner, Aarts, \& de Vries, 2008).

In terms of media habits, context has been repeatedly appointed a crucial role. In naturalistic, in situ research based on diaries, Ji and Wood (2007) found that the habit of watching news on television is cued by location, the time of day, mood and the presence of particular other people. A longitudinal study of students changing university revealed that a new, incongruent context disrupts habits, especially when those habits are strong. Students who perceived their new environment as very similar to their old one kept watching television at a relatively constant level. In contrast, those who considered their context as different diminished their viewing time. Yet, no differences occurred when the habit of watching television was initially weak. When context change was constrained to location (i.e. whether the behavior is usually performed in a fixed place, as opposed to different places), it appeared that diversity brought about a disruption, and subjected behavior to intentional control again. That is, students were again intentionally deliberating whether they would watch television. 
This was the case for those who had little to no habit, or those who had strong prior habits and wound up in another context. On the contrary, a renewed intentional control was not experienced by students with strong television viewing habits who were not subjected to a sudden variability in their viewing contexts. In the same study, it appeared that a disruptive social context had a similar effect on the habit of reading a newspaper. Again, those with a strong habit reverted to intentional deliberation (Wood, Tam, \& Witt, 2005).

Evidence of context dependency is also found in naturalistic research, in a real-world setting. Much research on basic psychological principles is based on laboratory research, aiming to understand what can happen, rather than what spontaneously does happen in everyday settings. In this respect Neal and Wood (2007) argue for combining both types of research, also pointing to their convergence in findings: 'data from the lab and from everyday life agree that habits tend to be triggered by contexts, including people, places, times of day, and preceding actions, with only minimal conscious monitoring'. In a study based on experience sampling (Wood, et al., 2002), i.e. filling out a diary at hourly intervals, indicated by a chiming wrist watch, participants were asked to indicate what they were doing, whether they considered it a habit and what their thoughts were. Media consumption made up fourteen per cent of all diary entries, and was categorized as habit in 54 per cent of the cases. A further analysis of television viewing, which was reported habitual in half of the cases, revealed that when reported as a habit, it was tied less often to corresponding thoughts (e.g. thinking about the answers of a quiz) than to non-corresponding thoughts (e.g. I am hungry). This would indicate that habitual behavior is much more automatic, and thus void of explicit thought.

Still, not all research corroborates the importance of context in media habit research. As mentioned by LaRose (2010), Ajzen (2002) argued on the basis of a secondary data analysis of Ouelette and Wood (1998), that in case of television viewing, context stability does not seem to matter. In the original study, context stability was assessed by the degree to 
which the behavior was consistently preceded by other activities. When the prior sequence would be relatively fixed, it was considered a stable context. The correlational analysis, based on longitudinal data with a three-week interval, showed that there was no significant difference between stable and unstable context in the correlation of watching television at the first and second measurement interval. Intentions also correlated with later behavior, albeit not differing between the conceptions of stable and unstable context.

The apparent ambiguity in empirical evidence causes LaRose (2010) to wonder whether media habits should be treated like any other. He argues that although a disruptive context might weaken habits, they may still tend to survive, and perhaps grow context independent. More specifically, he distinguishes between the process of habit formation, and its mere execution when it is established. In the former case, context has to be stable, whereas he theorizes that in the latter situation, this necessity evaporates. Hence, at this point there is a need for a much wider body of research on media habits in various contexts. The aim of this study is to contribute to this debate.

In this study, our first research question is directed at the substrate of the three context patterns derived earlier. These patterns reflect either the classic scheme of living room viewing together with family, an extension of this pattern by broadening viewing to various other socio-spatial contexts, and finally, a pattern of relative dislocation, in which the classic setting is at least partly traded in for more privatized viewing. The primary emerging question focuses on the extent to which these consumption patterns are explained by strong habits, as opposed to motivation.

$R Q$ 1: How do goals and habits relate for different patterns of socio-spatial context of audiovisual media consumption?

\section{Understanding the socio-spatial}


Although little research addresses the topic of media routines (of habitual behavior), there are perspectives that incorporate it as a core element. For instance, Domestication Theory focuses on the appropriation of media technologies in everyday life routines (Haddon \& Silverstone, 2000; Silverstone, 1994; Silverstone \& Haddon, 1996). The tenets of this perspective have been especially influential in European audience research, in a sense that it provoked what is referred to as the ethnographic turn in reception studies (Livingstone, 2003). That is, the acknowledgement that the sense-making process of media consumption extends beyond media texts as it also holds a material dimension. In other words, it broadened the research subject from what is on the screen to what is surrounding it. The domestication perspective posits that media technologies are first commodified by their producers. They are ascribed meanings through marketing communication that are then negotiated by consumers. This negotiation is not so much an individual process, as it must fit the moral economy of the home, reflecting the household's internal system of prevailing values, cognitions and aesthetic beliefs (Silverstone, Hirsch \& Morley, 1992). This is often a difficult exercise prone to trial and error in granting the technology not only the appropriate physical space, but also in incorporating its use in consumers' everyday life routines. Simultaneously, through their use, the negotiated consumption meanings are further transferred into the public, so they confound with producers' meanings.

When reviewing the Domestication perspective, one can see various similarities with Social Cognitive Theory's rationale as reflected in the Theory of Media Attendance (TMA). Both perspectives entail a social learning process that combines vicarious and enactive experiences. Moreover, they both seek to uncover how media are made meaningful by their consumers and how media consumption turns into a habit or routine. Nonetheless, despite a shared social-constructivist ontology, they differ in their epistemological positions. Whereas the TMA takes an objective stance, pointing its arrows at explaining behavior in terms of 
causal relationships, Domestication adheres to a subjective position, aiming to understand media consumption as a social phenomenon best inquired from the inside. What is more, in principle, their units of analysis diverge as the TMA zooms in on the individual, while Domestication looks beyond and focuses on household dynamics. From a pragmatic point of view, however, we strongly believe that both perspectives are compatible and add to each other. This sentiment is shared by Schrøder (1999) who applauds inter-paradigmatic research between $U \& G$ and ethnographic audience research. He refers to the need of drawing maps on different scales, however warning for all too simplistic notions of triangulation in which methodological imperfections would cancel each other out. Hence, it is imperative to strive for a design that transcends the sum of its constituents.

In this specific case, we believe this is feasible. The first research question invites a systematic oversight of the habit-goal interface for different socio-spatial consumption patterns. As such, using the TMA renders an overviewing map in the form of effects of habit and goals for different types of viewing environment. However, if we were to find that different socio-spatial contexts affect these relations, there would still be a need to understand what this might actually mean. This is where the Domestication perspective could make an indispensable contribution (i.e. a detailed map on a much smaller scale). More specifically, it offers the potential to provide insights in the meaning of specific sets of socio-spatial cues. That is, how and why they set off habits in the geography of the everyday life. Hence, we propose a second research question:

$R Q$ 2: How can we understand the role of socio-spatial cues in the habit-goal interface?

\section{METHODOLOGY}

In order to answer these two research questions, an integrated funnel approach was implemented. In a first phase, we devised a large-scale paper \& pencil survey with operational 
measures drawn from the TMA. Moreover, as will be discussed in the measures section, we included a set of items inquiring how often respondents consume audiovisual media in what spatial and social environment. These variables were then subjected to a latent class analysis (Vermunt \& Magidson, 2006), rendering a number of distinct patterns of consumption environments. As a consequence, these patterns allowed a multi-sample analysis of the Model of Media Attendance. Subsequently, results were used to sensibly recruit participants for a follow-up phase, consisting of domestic interviews. Chosen on the basis of very high to even absolute membership probabilities, the interviewees were treated as representatives for their respective classes. In the interview, we tapped into the meaning of the socio-spatial and how it allows the exercise of everyday media consumption routines.

To operationalize audiovisual media consumption we subscribe to an empirically grounded recommendation for an agnostic approach towards media consumption (Courtois, Verdegem, \& De Marez, 2011) Simply referring to 'television' can be very misleading, because, in the current circumstances, it is unclear for researchers as well as respondents what is meant by it. As such, it seems more productive to address it as a container concept that entails an accumulation of all instances. Moreover, we believe this is most productive when the objective is to sketch an oversight (i.e. the broader picture).

Furthermore, we make another important choice by explicitly incorporating the distinction between modes of consumption. As we consider stereotypical television viewing as a relative point of departure, we need to take into account that television has been mainly used in a physicallypassive state. That is, in a lean back fashion. This has been debunked by adding interactive features to the television experience (i.e. affordances of interactive digital television). Moreover, other devices such as laptops, desktops and mobile devices are often used in a different physical setting (e.g. at a desk, on the move), which is in most cases a lean forward experience. However, we by no means wish to argue that a device has an inherent 
lean back or lean forward nature. There are no predefined ties, as both types of behavior can be furnished. For example, a laptop can afford watching a short news clip at a desk during a surfing session. Likewise, users can make themselves comfortable, watching a film or series on the very same device. As a part of adapting our operational measures to the reality of convergent media consumption, we feel a need to maintain a heuristic distinction between both viewing modes. This is informed by literature on human-computer interaction (Ruy and Wong, 2007; Tsekleves et al., 2011). More specifically, we discern between a dedicated lean back viewing style and a lean forward style. The former most closely resembles 'television viewing' as it is classically seen. The latter is characterized by an 'in-between', consumption mode associated with seeking behavior, which is especially furnished by various new interactive applications. In the survey questionnaire, both viewing styles were aptly, yet thoroughly introduced and familiarized by a situational sketch. That is, an image and a description of the viewing behavior. We described the mindset of both behaviors and included a drawn sketch of a user's comportment during the specific type of behavior. Throughout, it was emphasized that viewing entails (professionally) edited video, which does not require action beyond selection. The frequency of such behavior, serving as the dependent variable in the eventual model, measured as a function of consumption one and two days before survey administration, was of course collected for both lean back and lean forward consumption. Likewise, lean back and lean forward applications of the expected outcomes and habit strength measures were obtained.

\section{Survey procedure and measures}

The paper and pencil questionnaire was administered on a large quota sample. It targeted three age cohorts equally dispersed over gender: young adulthood (18-30y), middle adulthood (31-50y) and late adulthood (50y+),. The data were gathered during NovemberDecember 2010 as a practical task within a research methods seminar at a large university in 
Belgium, Europe. This led to a total number of 1,559 valid responses (51\% male, $49 \%$ female; $\left.M_{\text {age }}=40.61, S D_{\text {age }}=16.79\right)$. The following paragraphs enumerate the applied measures.

Socio-spatial viewing context entails nine dichotomous items inquiring whether a number of social contexts (e.g. alone, with partner) and spatial contexts (e.g. living room, bedroom, hobby room) are used at least once every two to three days (yes or no). These variables are used to form latent classes of socio-spatial viewing contexts (see Table 2 for a full enumeration).

The measures below, which make up the Model of Media Attendance, were gathered for lean back viewing as well as lean forward viewing. The constructs' means, standard deviations and measures of internal consistency (Cronbach's $\alpha$ ) are summarized in Table 1.

Habit strength was assessed by Verplanken and Orbell's Self-Report Index of Habit Strength (2006). There are various ways of measuring (proxies) of habit strength, but when the aim is to gather self-reported, self-administered information, the SRHI is considered the most valid and reliable solution (Verplanken, Myrbakk \& Rudi, 2005). In line with current applications, items concerning past behavioral frequency were omitted (Verplanken, 2006). The ten remaining items were rated on a seven-point Likert scale ranging from 'totally disagree' to 'totally agree'. Sample items are: watching lean back (lean forward) is something I do without thinking', 'is something I find hard not to do', 'is something I do automatically'.

Expected outcomes were measured by twelve items drawn from previous research (LaRose \& Eastin, 2004; Peters, et al., 2006). The original items were slightly adapted to fit audiovisual consumption. The four most recurrent expected outcomes that match U\&G research on television, and hence audiovisual consumption, were retained (LaRose, et al., 2001). Hence, novel, social, activity and self-reactive outcomes were assessed with sevenpoint Likert scales, ranging from 'very unlikely' to 'very likely'. All items and confirmatory 
factor analysis results are incorporated in the Appendix section. Each item was preceded by the sentence 'how likely is it that the lean back [or lean forward] viewing of moving images...'.

Consumption frequency was measured by inquiring the hours and minutes spent on viewing moving images one and two days before the survey administration. This measure's metric was eventually converted to minutes.

\section{$\langle$ Table 1>}

\section{Interview procedure and topics}

The follow-up interviews were conducted with 28 participants recruited from the initial survey's respondent pool (18 females, 10 males, aged 18-63). Each interviewee counted as a typical case for a specific socio-spatial context class. Interviewees were dispersed over classes according to class sizes. The semi-structured interviews took place in the participants' domestic environments and lasted about one hour. The participants were first asked to draw a ground plan of their house, labeling all the rooms and indicating device locations (Figure 1). It was also extended with non-domestic locations in which regular consumption takes place. The ground plan was then used to map social interactions and socio-spatial meanings. More specifically, the interviewees were invited to sketch a day in their life onto this map and talk about how audiovisual media consumption fits into that. This implicitly covers temporal context, which in practice strongly coincides with the socio-spatial (Courtois, Verdegem, \& De Marez, 2012). In the meanwhile, we tapped into notions of stable context cues and overtime changes in habits (e.g. by disruption or life events). The interviews were coded using a deductive coding scheme, based on the literature discussed in the introduction (i.e. key aspects of Domestication Theory and the socio-cognitive literature on habit formation). In the analysis, patterns with class membership were actively sought, while pursuing a deepening account of the results that were drawn from the survey, discussed in the following sections. 


\section{RESULTS}

\section{Socio-spatial viewing classes}

To distinguish between different socio-spatial context configurations, a latent class analysis (LCA) is performed on a set of nine dichotomous indicator variables. By means of an LCA, distinct latent patterns are revealed within multivariate categorical data. A common strategy to discern the most suitable model is to iterate the analysis with an increasing number of classes until a satisfactory model fit is reached. In this case, a three-class model appears to be the most parsimonious, well-fitting solution $\left(L^{2}(1530)=619.31, p=1\right)$. Table 2 summarizes the response probability per class to watch in that social/spatial context at least once every two to three days.

\section{$<$ Table 2>}

The unispace-social viewers display relatively high probabilities of engaging in social viewing, while mostly situated in the family living room. This is echoed by multispacesolo/social viewers, although they also have much higher chances of solitary viewing. As such, they appear to combine both solitary and social orientations. Moreover, their consumption is located in a variety of places, most likely situated in the domestic environment. Finally, the multispace-solo viewers display a relatively high chance to view in solitude, situated in the bedroom, followed by the living room.

These results indicate a strong divergence in everyday socio-spatial configuration of audiovisual media consumption. Moreover, they are strongly associated with demographic variables such as age and gender (Table 3).

\section{$<$ Table 3>}

\section{The habit-goal interface}

To address the first research question, a structural equation model is specified for each viewing style, regressing consumption onto its respective expected outcomes and habit 
strength. The analyses were ran for all three distinguished subsamples, reaching a satisfactory overall goodness-of-fit of the lean back $\left(\chi^{2}(56)=241.37, \mathrm{TLI}=.92, \mathrm{CFI}=.93, \mathrm{RMSEA}=\right.$ $.05)$ and the lean forward constrained measurement models $\left(\chi^{2}(56)=274.36\right.$, TLI $=.91$, CFI $=.94$, RMSEA $=.05)$. Next, both paths towards consumption, situated in the structural model (A and B in Figure 2), were constrained to equality in order to identify the strongest explanatory factor. That is, we compare per class and viewing type whether a seeming difference in the unstandardized path coefficients A and B reflects a significant difference. If the $\Delta \chi^{2}$ proves to be significant at $p<.05$-level, we can conclude the paths differ in magnitude. Otherwise, we cannot draw such a conclusion and most treat them as equal in size.

$<$ Figure 2>

Table 4 summarizes the analyses' results. It clearly shows that expected outcomes and habit strength are both strong explanatory factors of a comfortable, lean back consumption. Nonetheless, the strength of these effects varies between socio-spatial classes. The consumption of the two social viewing classes is mostly explained by habit strength, rather than expected outcomes. This suggests that for these classes, the consumption of audiovisual texts is something that is strongly embedded within everyday routines, while not so much inspired by individual deliberate considerations. For the multispace-solo viewers this is not quite the case, as both factors yield similar effects. Hence, its members' audiovisual consumption is equally driven by deliberative choice and habit. Still, lean forward viewing is consistently explained by habit strength, whereas the effects of expected outcomes only yield a small significant effect for the multispace-solo viewers. This suggests that lean forward viewing is more circumstance-based than lean back viewing. An effect of habit but not expected outcomes points to a non-deliberative engagement, rather than a specific choice to approach audiovisual media in such a constellation. 
Although these results offer insight in what lies at the core of audiovisual media consumption, they immediately give rise to questions on how we can understand these relations and how they are rooted within everyday life. Therefore, in the following paragraphs, we provide a direct link with the subsequent domestic interviews that were performed with typical cases from each socio-spatial context class.

\section{Class 1: Unispace-social viewers}

In recapitulation, this class predominantly consists of somewhat older people (Table 3). Their consumption of audiovisual media happens in the living room, preferably with their partners and to a lesser extent with other family members. On a daily basis, over two hours are spent watching in a comfortable lean back manner, while about twenty minutes are allocated to lean forward viewing. Both behaviors are quite strongly explained by habit, whereas only lean back viewing is deliberated.

In the interviews, we noticed that this class' participants maintain very rigid, traditional cognitive schemes of consumption geography. Their living room, where the bulk of lean back viewing is performed, is in all cases oriented towards a television set. When the participants were inquired about why they locate their consumption in that specific space, they find it rather difficult to explain. They attribute it to the fact that it has always been like this and that is should not be put into question:

Daniël $(63, \mathrm{M})$ : Eventually, it's a habit you just took up. Why do we have a TV? You don't think about that. It's a habit that has been taught to you as a child, that you have to watch there [the living room] And so it was one of the first things we bought of the things that are present here. [...] Anyway, not in in the other rooms... they're not that cozy, because... because when you're there, you are isolated, unless you would tell the others to join you in that room. No, I don't feel the need to watch somewhere in 
complete isolation. That's mainly the reason why I feel no urge to have devices in the other rooms.

The living room is consistently and spontaneously called a space to watch, indicating it to be a stable environment for consumption. In fact, when the habit would be disrupted, for instance by a broken device, it would be immediately replaced by a similar one. Moreover, as Daniël put it, the living room is unanimously considered a warm and cozy environment, equipped with comfortable furniture that affords to sit back or even lie down. Equally important is that living room consumption is actually heavily intertwined with the household's social dynamics. Watching television at night, after dinner, is considered a social lubricant that makes up a valuable part of family life, which corresponds with Lull's (1990) findings, even over twenty years ago. Other spaces, like bedrooms or kitchens, are deemed unsuitable because they are much more individualized and furnish other activities that are not compatible with this social character. Although some time is spent watching alone, other family members usually join them (although of course this also happens the other way round). Furthermore, as the participants from this class exercise hegemonic roles in the family's moral economy, they are able to steer its consumption. First of all, they exercise control over the remote control, either deciding what is watched or at least moderating the preceding family discussion. In fact, we encountered several instances in which such discussions were regarded beneficial in learning how to give and take. Second, the participants in this class play a decisive role in determining the amount, nature and place of technologies in the home. And third, they are able to engage in rule making. In fact, the parents we interviewed, especially those of younger children and teenagers, claim discomfort with the evasion of the living room, however not necessarily preventing it. For example, Helen's $(42, \mathrm{~F})$ television set is located in the living room. There is one that is used upstairs, yet only during ironing. As a mother of two, she 
actively prevents her boys from watching that set. When we asked her about her opinion on family viewing, she told us:

Helen: Yeah, that is the norm in society, that it is something you do together. In my case, watching alone would be bizarre. Anyway, it's a normal activity to do in company, like playing a game, that's something you don't do by yourself either. It is something you do with your family...

On the contrary, lean forward viewing is often linked to other devices like computers that are more spatially dispersed and that involve a more individualized approach. This experience is severely influenced by the lack in comfort, sitting alone on a chair, at a table or desk. This contrasts with the comfortable situation previously described. Consequently, deliberate consumption is very rare and is limited to very few occasions. More often, lean forward consumption is unplanned and is triggered by event-based onset stimuli such as email links or events during web surfing (i.e. it is unplanned and happens in conjunction with other, albeit planned activities). Hence, the lean forward consumption here could be seen as part of a larger script of web browsing routines, and not an activity as such. Furthermore, we do find traces of how people try to match the surroundings of both viewing styles, and even combine them so they would link. They do so for instance by locating the computer in the living room, so they would still be in the presence of family members, and even join in their activities from a distance. Hence, we notice how the dynamics of this separate viewing style are integrated in family interaction.

\section{Class 2: Multispace-solo viewers}

This class is the youngest one with a median age of 20 years old. In comparison to other classes, they are much more likely to watch in the solitude of their bedrooms, away from a more socially oriented living room. On average, they consume 80 minutes per day in a lean back mode, while their lean forward consumption amounts to half an hour. The relations 
between the underlying factors of lean back viewing are interesting. In contrast with the other two classes, there is no significant difference between both explanatory paths. This implies that their lean back consumption is equally directed by expected outcomes and habits. Still, the interviews allowed an understanding of this occurrence. It appears that these younger people strive for consumption autonomy, thus avoiding the living room, especially when there is ground for familial conflict (e.g. disputes about what to watch and when to watch it). In fact, technological diversification allows avoiding dissatisfaction (as described in Lull, 1990), by offering multiple means to the same end. When they watch, they want to be able to make deliberate choices and keep away from disfavored social interaction. Still, they do cherish the living room and actually revert to it in particular situations in which they sense it adds value to the experience. This is articulated by Vera $(21, \mathrm{~F})$, who combines consumption in the living room, her own bedroom and her brother's bedroom:

Vera: The living room's major attractor is that it's homely; my parents watch here [the living room]. It is also something that is printed into us; it's a family value. Watching together with my [younger] brother, in his room is something recent, but then I'm in his personal space. I don't feel like an intruder, but it is a different feeling. I would never watch there without him. Here that's different because it's a shared space. Then again, with him it is different, a brother-sister thing, without the parents. Just the two of us, which gives me the feeling to be closer to him, to do the things he likes. Here, it's more general, depending on what everyone likes. In my own room, it's very personal, the things I want to see, the series I want to watch and of course also other stuff like my e-mail, Facebook,... things the other family members have no business with.

In some cases, for instance when there is a joint preference for a certain program, the living room is valued as a social space. Yet even more important is that multi-space solo viewers too cherish the living room as a comfortable environment (e.g. warm, cozy sofa, ideal viewing 
position). Interestingly, this class' members put in quite some effort to replicate cues from this space into their own private spaces. In fact, they actively pursue to make a 'living room' for their own by incorporating a sofa, modifying their beds while watching and arrange their televisions or computers to get a similar viewing position.

Furthermore, the statistical analysis has shown that, next to habit strength, expected outcomes also explain variance in lean forward consumption. In fact, the interviews revealed a slightly different interaction with lean back viewing. In the previous case, both were mostly separated. This type of viewers, however, often uses a computer for both consumption types, situated in the same room. Hence, there are notions of interaction for instance when coming across interesting content, that is actively searched and previewed in a lean forward manner and then later on consumed in a lean back fashion. Still, the transition from one type to the other involves an active rearrangement of the affording device and its immediate surroundings. In other words, lean forward viewing tends to serve as a motivated cue for lean back viewing.

\section{Class 3: Multispace-social and solo viewers}

Finally, the third class consists of people somewhat older than the one previously discussed. Their daily lean back consumption roughly amounts to two hours, while they allocate more than half an hour to lean forward viewing. The relations between the underlying factors closely resemble those of the first class we discussed. Nonetheless, they diverge strongly in the socio-spatial contexts of consumption. Drawing upon the interviews, it shows that this class, similar to the previous one, experiences some tensions that require more dispersed viewing patterns. Still, there are accounts of individualized viewing without any specific need to do so. Although they too maintain the living room as a primary site of (social) consumption, they themselves tend to view in other rooms as well, be it to avoid tensions or not. The question is what separates them from the people in the first class. Whereas those 
were strongly tied to a joint experience, the participants from this class have a more balanced consumption. They hold tight to socially oriented viewing. Thisis combined with a more individualized consumption, however. IT-consultant Jasper (26, M) lives together with his girlfriend, in a house packed with multiple screens:

Interviewer: some people watch with their family, do you do that too? Jasper: No, not really. Yeah, there are some shows we watch together. Otherwise, we really enjoy being in separate places, to have 'me-time'. And that's something important for me, you know, I was brought up that way. I need some time to spend by myself. I think it's really important for people to have their own space, a personal space in the house.

The origins of this behavior are manifold. One way to understand it is that similar meanings are attributed to various spaces. More specifically, cognitive schemes for certain spaces tend to overlap, for instance when the kitchen and the living room are perceived equal in terms of sites of family life, or viewing the bedroom as equally pleasant for quality time with a partner. In that case, audiovisual technologies have similar probabilities of entering that space or that kind of social interaction. This suggests that strongly formed habits have the ability to extend beyond contexts and even grow largely context-independent, hence surviving disruptive contexts (see LaRose, 2010 and Wood, Tam, \& Witt, 2005). For example, as a paramedic, Victor $(23, \mathrm{M})$ uses his laptop at the hospital's breakout room to fill his stand-by time. The living room-like environment makes him feel sufficiently comfortable to consume video over there. Still, his story seems rather exceptional (which is also reflected in the results of the LCA), as all the other participants report only few occasions when they would watch outside the home (e.g. during work-out at a fitness center, at work while browsing the Web during lunch). They all agree on the dedicated and most often intimate nature of kind of 
media consumption, which is only rarely furnished outside the domestic sphere. This immediately narrows the scope of mobile devices, which are hardly mentioned spontaneously.

However, we noted another interesting pattern. When we inquired about the occurrences that made them shift away from living room viewing, participants mentioned their consumption as teenagers. They reflect upon their autonomous use back then, having a television in the bedroom or some hobby space. Also, they touch upon their experiences as students, having a personal device in their student room in order not to disrupt their former media habits. As such, they learned a more individualized behavior that is much less contingent on social cues, causing an alteration of that habit. This is for instance the case for Erik (30, M). Before he had a television in his room as a teenager, he used to watch together with his family. From then on, his viewing individualized, through the already mentioned substitution of the 'living room experience' by arranging one of his own. Later, when he went to university, he had to have a set in his dorm too. Nowadays, he lives together with his girlfriend and although they watch together regularly, unlike his girlfriend, he does not mind to go to another room to catch up with series episodes or watch sports on his own.

\section{DISCUSSION}

In our research, we found that audiovisual viewing behavior is in the first place explained by habits, and by expected outcomes in second instance. In general, the results indicated that this especially holds up for all three distinct patterns of socio-spatial consumption contexts, albeit more pronounced for lean forward viewing. As argued, both viewing types are substantially rooted in social and spatial routines. The counter-intuitive result that lean forward viewing is hardly explained by expected outcomes is likely attributed to the finding that the activity is usually strongly embedded in broader new media browsing and consumption routines. 
Consumption in the distinguished environments is differentially explained by goaldirected expected outcomes and habits. The group of unispace-social viewers adheres to the traditional scheme of living room family viewing, which is strongly explained by habit. This is also the case for the multispace-social/solo viewers who demonstrate a complex configuration of numerous consumption environments, combining both individualized and joint experiences in multiple settings. Furthermore, we discovered a group of multispace-solo viewers who commute from the private bedroom to the living room, seeking an autonomous experience.

In elaborating on these statistical effects, we explored how routine patterns are best understood through the concept of the moral economy of the home. That is framing the household as a dynamic micro-economic entity in which values, cognitions and aesthetics are transferred between the constituent members from different generations. By combining this analytical framework with theoretical accounts of habit formation and execution processes drawn from social psychology, we were able to understand the habit-goal interface in audiovisual media consumption. More specifically, we discovered that the unispace-social viewers have no incentive to change their viewing patterns as they highly value family viewing and are able to exercise a more dominant role in promoting this kind of consumption. Even in situations where for instance spouses disagree, there is a tendency to put up with it, rather than seeking alternatives. As such, they are inclined to perceive the living room as the one and only stable context. The multispace-social/solo viewers are however detached from this belief, displaying leniency towards more individualized viewing for themselves as well as the other family members. By means of the interviews, we were also able to trace the origins of this behavior and noticed that these viewers have a less compartmentalized conception of their homes and explicitly equate the meanings of several socio-spatial locations. Moreover, we came across notions of habit reconfiguration as a result of individualized viewing behavior 
as a teenager. This links in with the younger multispace-solo viewers who actively seek a disconnection from family viewing in order to make decisions of their own, which links in with earlier developmental-psychological theoretical and empirical accounts of teenage bedroom media consumption (Courtois, Mechant, Paulussen, \& De Marez, 2011; Livingstone, 2002). However, it seems they actively pursue to incorporate cues from the living room into their new consumption contexts, rendering it equally stable contexts in socio-spatial terms. Still, much more research is needed in order to strongly put forward such a causal claim. Furthermore, we do not know about the dimensions of controllability, and how this plays down in appropriating behavior in new or uncommon contexts.

Still, this enables an understanding of today's changing (audiovisual) media consumption that appears to be a mix of cohort and life stage effects. Whereas older generations have learned a strong association between the audiovisual and social viewing, younger generations have the opportunity to get used to a more individualized experience. This culminates in the teenage years, appearing to decline later on when new life stages are entered, yet leaving seemingly permanent traces. As such, traditional television viewing as a shared activity bound to the living room persists, and will most likely keep on persisting, despite important deviation and extensions in terms of time and space.

\section{CONCLUSION}

This article sheds light on the origins of audiovisual media consumption. This is accomplished by a combination and integration of multiple theoretical accounts and their respective methodologies. Although Social Cognitive Theory and Domestication Theory diverge in their epistemological positions, we believe that by actively integrating its results, a more refined approach to the subject is rendered feasible. The questionnaire, based on operational quantitative measures derived from earlier work on the TMA, has allowed us to sketch a broad map of patterns of consumption. To our knowledge, this is the first research 
that looks for a way to detach U\&G/TMA measures from a specific manifestation of device, content or socio-spatial context. In the age of convergence such an agnostic view is although very abstract - productive when the aim is to grasp the broader picture, rather than focusing on one of its fragments. This allows relations with various external measures, in this case socio-spatial context, allowing for investigating the changing media environment. Furthermore, by adding an in-depth qualitative layer guided by both Domestication and social-psychological concepts, we were able to obtain an understanding of the processes and dynamics that underlie these preliminary results. Our research strengthens Domestication Theory's claim that the appropriation of media is a never-ending, dynamic process, driven e.g. technological advancement and family dynamics. Hence, we want to make a case for more integrated accounts by embracing a pragmatic stance towards different paradigms, looking for what unites, rather than for what divides.

In practical terms, this study shows a nuanced view on how audiovisual audiences have (not) changed and are (not) changing. This kind of insight is indispensable for both commercial and public service broadcasters to engage with their target audiences. It allows them to devise a multi-platform programming strategy that fits the audience's needs in terms of content, informed by the situation they are in. Finally, we propose multiple venues for future research. On the one hand, the Model of Media Attendance, as we implemented it, could be applied to other kinds of media consumption and/or could be extended by various measures, depending on the research topic. Still, we are - based on our findings - very much in favor of adding developmental factors and, if possible - adding multilevel factors such as individuals and families. The qualitative layer should be opened up to all kinds of traditions that embrace in-depth qualitative, or even ethnographic accounts of the social phenomenon of media consumption. In that respect, we stress the necessity to add more contextual factors. 
For instance, we did not explicitly take into account emotional and affective states, although these shimmered through talking about socio-spatial context. a

\section{REFERENCES}

Ajzen, I. (2002). Residual effects of past on later behavior. Organizational Behavior and Human Decision Processes, 50(179-211).

Courtois, C., Mechant, P., Paulussen, S., \& De Marez, L. (2011). The Triple Articulation of Media Technologies in Teenagers' Media Consumption. New Media \& Society.

Courtois, C., Verdegem, P., \& De Marez, L. (2011). Audiovisual consumption as the interplay of objects, texts and contexts. Paper presented at the EuroITV 2011, Lisbon, Portugal.

Danner, U. N., Aarts, H., \& de Vries, N. K. (2008). Habit vs. intention in the prediction of future behaviour: The role of frequency, context stability and mental accessibility of past behaviour. British Journal of Social Psychology, 47(2), 245-265.

Galloway, J. J., \& Meek, F. L. (1981). Audience Uses and Gratifications: An Expectancy Model. Communication Research, 8(4), 435-449.

Haddon, L., \& Silverstone, R. (2000). Information and Communication Technologies and Everyday Life: Individual and Social Dimensions. In K. Ducatel, J. Webster \& W. Herrmann (Eds.), The Information Society in Europe. Lanham: Rowman \& Littlefield Publishers.

Ji, M. F., \& Wood, W. (2007). Purchase and consumption habits: Not necessarily what you intend. Journal of Consumer Psychology, 17(4), 261-276.

Katz, E., Blumler, J. G., \& Gurevitch, M. (1974). Utilization of Mass Communication by the Individual. In J. G. Blumler \& E. Katz (Eds.), The Uses of Mass Communication. London: Sage Publications.

LaRose, R. (2010). The problem of media habits. Communication Theory, 20(2), 194-222. 
LaRose, R., \& Eastin, M. (2004). A Social Cognitive Theory of Internet Uses and Gratifications: Toward a New Model of Media Attendance. Journal of Broadcasting \& Electronic Media, 48(3), 358-377.

LaRose, R., \& Kim, J. (2007). Share, steal, or buy? A social cognitive perspective of music downloading. Cyberpsychology \& Behavior, 10(2), 167-277.

LaRose, R., Mastro, D., \& Eastin, M. (2001). Understanding Internet Usage: A SocialCognitive Approach to Uses and Gratifications. Social Science Computer Review, 19(4), 395-413.

Lee, D., \& LaRose, R. (2007). A socio-cognitive model of video game usage. Journal of Broadcasting \& Electronic Media, 51(4), 632-650.

Livingstone, S. (2002). Young People and New Media. London: Sage.

Livingstone, S. (2003). The changing nature of audiences: From the mass audience to the interactive media user. Oxford: Blackwell.

Neal, D., \& Wood, W. (2007). Automaticity in situ: The nature of habit in daily life. In J. A. Bargh, P. Gollwitzer \& E. Morsella (Eds.), Psychology of action (Vol. 2): Mechanisms of human action. New York: Guilford Press.

Ouelette, J. A., \& Wood, W. (1998). Habit and intention in everyday life: The multiple processes by which past behavior predicts future behavior. Psychological Bulletin, $124,54-74$.

Palmgreen, P., \& Rayburn, J. D. (1985). An Expectancy-Value Approach to Media Gratifications Media Gratifications Research: Current Perspectives. London: Sage Publications.

Peters, O. (2009). A social cognitive perspective on mobile communication technology use and adoption. Social Science Computer Review, 27(1), 76-95. 
Peters, O., Rickes, M., Jöckel, S., Von Criegern, C., \& Van Deursen, A. (2006). Explaining and analyzing audiences: A social cognitive approach to selectivity and media use. Communications, 31(3), 279-308.

Rubin, A. M. (1983). Television uses and gratifications: The interactions of viewing patterns and motivations. Journal of Broadcasting, 27(1), 37-51.

Rubin, A. M. (1984). Ritualized and Instrumental Television Viewing. Journal of Communication, 34(3), 67-77.

Rubin, A. M. (2002). The Uses-and-Gratifications Perspective of Media Effect. In J. Bryant \& D. Zillman (Eds.), Media Effects: Advances in Theory and Research. Mahwah: Lawrence Erlbaum Associates.

Ruggiero, T. E. (2000). Uses and gratifications theory in the 21 st century. Mass Communication \& Society, 3(1), 3-37.

Schrøder, K. C. (1999). The best of both worlds? Media audiences research between rival paradigms. In P. Alasuurari (Ed.), Rethinking the media audience: the new agenda (pp. 38-67). London: Sage.

Silverstone, R. (1994). Television and Everyday Life. London: Routledge.

Silverstone, R., \& Haddon, L. (1996). Design and the domestication of information and communication technologies: technical change and everyday life. In R. Mansell \& R. Silverstone (Eds.), Communication by Design. Oxford: Oxford University Press.

Van Leuven, J. (1981). Expectancy Theory in Media and Message Selection. Communication Research, 8(4), 425-434.

Vermunt, J. K., \& Magidson, J. (2006). Latent Class Analysis. from http://www.statisticalinnovations.com/articles/Latclass.pdf

Verplanken, B. (2006). Beyond Frequency: Habit as a Mental Construct. British Journal of Social Psychology, 45(3), 639-656. 
Verplanken, B., Aarts, H., van Knippenberg, A., \& Moonen, A. (1998). Habit versus planned behaviour: A field experiment. British Journal of Social Psychology, 37(1), 111-138.

Verplanken, B., \& Orbell, S. (2006). Reflections on Past Behavior: A Self-Report Index of Habit Strength. Journal of Applied Social Psychology, 33(6), 1313-1330.

Wood, W., \& Neal, D. (2007). A New Look at Habits and the Habit-Goal Interface. Psychological Review, 114(4), 843-863.

Wood, W., Quinn, J., \& Kashy, D. (2002). Habits in Everyday Life: Though, Emotion and Action. Journal of Personality and Social Psychology, 83(6), 1281-1297.

Wood, W., Tam, L., \& Witt, M. G. (2005). Changing circumstances, disrupting habits. Journal of Personality and Social Psychology, 88(918-933). 


\section{APPENDIX}

Expected outcomes scale. Both viewing type measures demonstrate a satisfactory overall measurement model fit on three random subsamples. Incremental $\chi^{2}$-tests indicate invariant measurement weights, intercepts and structural covariances. All indicators are significant at $p<.001$.

\begin{tabular}{|c|c|c|}
\hline Construct & $\lambda$ Lean back & $\lambda$ Lean forward \\
\hline \multicolumn{3}{|l|}{ Activity } \\
\hline Amuse yourself & .82 & .87 \\
\hline Have a good time & .78 & .88 \\
\hline Feel uplifted & .69 & .80 \\
\hline \multicolumn{3}{|l|}{ Novel } \\
\hline Get track of important news & .88 & .91 \\
\hline Keep track of events & .86 & .86 \\
\hline Learn new things & .53 & .67 \\
\hline \multicolumn{3}{|l|}{ Self-reactive } \\
\hline Enjoy the moment & .78 & .81 \\
\hline Forget daily burdens & .56 & .65 \\
\hline Relax yourself & .54 & .58 \\
\hline \multicolumn{3}{|l|}{ Social } \\
\hline Strengthen your social ties & .81 & .82 \\
\hline Share an activity & .72 & .80 \\
\hline Feel part of a group & .81 & .83 \\
\hline $\begin{array}{l}\text { Model fit on three random subsamples: } N= \\
520,483,471\end{array}$ & $\begin{array}{l}\chi^{2}(144)=619.42, \\
\text { TLI }=.91 \\
\text { CFI }=.93, \\
\text { RMSEA }=.05\end{array}$ & $\begin{array}{l}\chi^{2}(144)=400.46, \\
\text { TLI }=.94, \\
\text { CFI }=.96, \\
\text { RMSEA }=.04\end{array}$ \\
\hline
\end{tabular}


Table 1. Measures means, standard deviations and Cronbach's $\alpha .{ }^{\circ}$ because these are twoitem measures of time spent on audiovisual media one and two days before survey administration, correlations are reported instead of $\alpha$-coefficients.

\begin{tabular}{lllllll}
\hline Construct & \multicolumn{3}{l}{ Lean back viewing style } & \multicolumn{3}{c}{ Lean forward viewing style } \\
& $M$ & $S D$ & $\alpha$ & $M$ & $S D$ & $\alpha$ \\
\hline Expected outcomes & & & & & & \\
$\quad$ Social & 3.16 & 1.24 & .79 & 2.93 & 1.34 & .80 \\
Novel & 4.67 & 1.20 & .79 & 4.89 & 1.35 & .84 \\
Self-Reactive & 4.39 & 1.12 & .70 & 3.30 & 1.15 & .76 \\
$\quad$ Activity & 5.07 & 1.05 & .82 & 3.77 & 1.33 & .88 \\
Habit strength & 4.74 & 1.34 & .88 & 3.43 & 1.31 & .91 \\
Consumption frequency & 108.77 & 77.62 & $\left(r^{\circ}=.43\right)$ & 24.95 & 34.10 & $\left(r^{\circ}=.70\right)$ \\
\hline
\end{tabular}


Table 2. Latent Class Analysis. Response probabilities, Wald statistics and variance

explained. $* p<.05, * * p<.005, * * * p<.001$

\begin{tabular}{lccccc}
\hline & $\begin{array}{c}\text { Class 1: } \\
\text { Unispace- } \\
\text { social viewers } \\
(57 \%)\end{array}$ & $\begin{array}{c}\text { Class 2: } \\
\text { Multispace- } \\
\text { solo viewers } \\
(14 \%)\end{array}$ & $\begin{array}{c}\text { Class 3: } \\
\text { Multispace- } \\
\text { social/solo } \\
\text { viewers }(29 \%)\end{array}$ & Wald & $\mathbf{R}^{2}$ \\
$\begin{array}{l}\boldsymbol{p} \text { response } \\
\text { (at least every 2-3 days) }\end{array}$ & .65 & .60 & .93 & $29.02^{* * *}$ & .09 \\
\hline Alone & .40 & .00 & .38 & 4.52 & .09 \\
Family, other generation & .77 & .19 & .60 & $79.86^{* *}$ & .18 \\
Partner & .99 & .25 & .94 & $56.91^{* * *}$ & .56 \\
Living Room & .17 & .37 & .41 & $19.66^{* *}$ & .07 \\
Bedroom & .16 & .07 & .19 & $9.69^{* *}$ & .01 \\
Kitchen & .04 & .17 & .47 & $38.52^{* * * *}$ & .23 \\
Leisure Room & .07 & .04 & .38 & $51.13^{* * *}$ & .17 \\
Work/School & .00 & .00 & .05 & 3.47 & .03 \\
Commuting & & & & & \\
(Public transport) & & & & & \\
\hline
\end{tabular}


Table 3. Demographic background and consumption frequency within latent viewing classes.

\begin{tabular}{|c|c|c|c|c|}
\hline & $\begin{array}{c}\text { Class 1: } \\
\text { Unispace-social } \\
\text { viewers }\end{array}$ & $\begin{array}{c}\text { Class 2: } \\
\text { Multispace- } \\
\text { solo viewers }\end{array}$ & $\begin{array}{l}\text { Class 3: } \\
\text { Multispace- } \\
\text { social/solo } \\
\text { viewers } \\
\end{array}$ & $\chi^{2}$ \\
\hline Gender: & & & & $51.42 * * *$ \\
\hline Female & 56 & 52 & 35 & \\
\hline Male & 44 & 48 & 65 & \\
\hline Age: & & & & $200.69 * * *$ \\
\hline $\begin{array}{l}\text { Young adulthood (18- } \\
\text { 30y) } \\
\text { Middle adulthood (31- }\end{array}$ & 22 & 65 & 50 & \\
\hline $50 y)$ & 39 & 19 & 34 & \\
\hline Late adulthood $(50 \mathrm{y}+)$ & 38 & 16 & 16 & \\
\hline \multicolumn{5}{|l|}{ Age (years) } \\
\hline \multirow[t]{2}{*}{ Mdn } & 48 & 21 & 30 & \\
\hline & & & & $F$ \\
\hline \multicolumn{5}{|l|}{ Consumption frequency } \\
\hline Lean back (M, SD min) & $\begin{array}{r}124.02 \\
(101.01) \\
23.02\end{array}$ & $\begin{array}{r}78.17 \\
(90.03) \\
31.84\end{array}$ & $\begin{array}{r}107.90 \\
(74.24) \\
35.46\end{array}$ & $21.15 * * *$ \\
\hline Lean forward (M, SD min) & $(35.54)$ & $(.73 .80)$ & $(51.83)$ & $10.80 * * *$ \\
\hline
\end{tabular}


Table 4

Summary of the multi-group analysis of the media attendance model. The parameters are unstandardized and should be read as following: e.g. for Class 1, and increase of one unit in lean back expected outcomes is associated with 13.21 additional minutes of lean back consumption. + Parameters estimates when constraining measurement weights and intercepts to equality for all three classes. ++ Model nested within constrained measurement model. $* p<.05, * * p<.005, * * * p<.001$.

\section{Path specifications}

\section{Parameter estimates ${ }^{+}$}

Class 1:

Unispacesocial viewers

B
Class 2:

Multispace-

solo viewers
Class 3:

Multispacesolo/social viewers

$\mathrm{B}$

Lean back viewing:

Path A: Expected outcomes $\rightarrow$ Consumption

Path B: Habit strength $\rightarrow$ Consumption

Covariance C: Habit strength $\leftrightarrows$ Consumption

Variance explained in Consumption $\left(\mathrm{R}^{2}\right)$

Model with both paths constrained to equality: ${ }^{++}(\mathrm{A}=\mathrm{B})$

Lean forward viewing:

Path A: Expected outcomes $\rightarrow$ Consumption

Path B: Habit strength $\rightarrow$ Consumption

Covariance C: Habit strength $\leftrightarrows$ Consumption

Variance explained in Consumption $\left(\mathrm{R}^{2}\right)$

Model with both paths constrained to equality: ${ }^{++}(\mathrm{A}=\mathrm{B})$

$\begin{array}{llllll}13.21 * * * & 3.34 & 21.85 * * * & 4.85 & 8.04 * & 3.84 \\ 21.80 * * * & 2.03 & 13.58 * * * & 2.23 & 18.86 * * * & 2.02 \\ .74 * * * & .06 & .61 * * * & .10 & .36 * * * & .06 \\ .26 & & .41 & & .17 & \\ \Delta \chi^{2}=4.00 * & & \Delta \chi^{2}=2.03 & & \Delta \chi^{2}=5.27 *\end{array}$

$\begin{array}{llllll}1.10 & .96 & 2.95^{*} & 1.43 & .13 & 1.19\end{array}$

$\begin{array}{llllll}8.50 * * * & .62 & 8.68 * * * & .89 & 9.36 * * * & .62\end{array}$

$\begin{array}{llllll}1.07 * * * & .10 & 2.16^{* * *} & .25 & .88 * * * & .12\end{array}$

$\begin{array}{lll}.31 & .26 & .26\end{array}$

$\Delta \chi^{2}=39.15^{* * *} \quad \Delta \chi^{2}=9.56^{*} \quad \Delta \chi^{2}=37.10^{* * *}$ 
Figure legend:

- Figure 1: Example of a ground plan, drawn by one of the participants

- Figure 2: Specified structural equation model ran for both lean back and lean forward viewing styles. The figure contains standardized coefficients, first for lean back viewing, and second for lean forward viewing. All estimates are significant at $p<.001$ 